\title{
Uma mulher no seu tempo: ciência, arte e educação num percurso de vida
}

\section{A woman in her time: science, art and education in a life path}

\author{
Maria João Mogarro*
}

\begin{abstract}
RESUMO
Professora universitária de ciências e professora do ensino liceal, Seomara da Costa Primo (Lisboa, 1895 - Amadora, 1986) distinguiu-se como investigadora, autora (nomeadamente de manuais) e ilustradora. A sua ação incorporou também o associativismo docente, a participação na imprensa e missões de estudo no estrangeiro. Foi uma mulher do seu tempo, uma intelectual, que defendeu um papel ativo das mulheres na sociedade e lutou pela sua educação, afirmando-se num universo essencialmente masculino. O seu percurso vital demonstra que percorreu algumas das instituições de referência da época e dialogou em arenas significativas de debate, afirmando-se como uma personalidade ímpar que também circulou internacionalmente em missões científicas. A penumbra em que tem sido mantido o seu nome e a sua vida deve ser iluminada por uma recolocação na galeria das mulheres ilustres que representam um tempo e um modo de ocupar o espaço público e de afirmar a profissão docente.
\end{abstract}

Palavras-chave: Profissão docente. Universidade. Manuais. Seomara da Costa Primo. História das mulheres.

\begin{abstract}
Seomara da Costa Primo (Lisbon, 1895 - Amadora, 1986) was a science university professor and a high school teacher. She was a distinguished researcher, textbook author and illustrator. She was also part of teaching associations, was once part of the press and did study missions abroad. She was a woman of her day, an intellectual that defended the active role of women in
\end{abstract}

DOI: $10.1590 / 0104-4060.53320$

* Universidade de Lisboa. Lisboa, Portugal. R. Branca Edmée Marques, 1600-276. E-mail: mariamogarro@gmail.com 
society and fought for her education, empowering herself in a men's world. Her life path demonstrates that she was part of some reference institutions of the time and dialogued in significant arenas of debate, asserting herself as a personality who also circulated internationally in scientific missions. The penumbra in which her name and life have been kept must be illuminated by re-placing her in the gallery of illustrious women who represent a time and a way of occupying the public space and put the teaching profession forward.

Keywords: Teaching profession. University. Textbooks. Seomara da Costa Primo. Women's history.

\section{A vida e obra de uma intelectual cientista}

No final do século XIX, no dia 10 de Novembro de 1895, nasceu em Lisboa, a capital do país, Seomara Buttuller da Costa Primo, que viria a falecer nove décadas depois, na Amadora, em 2 de Abril de 1986. As suas origens situavam-na na classe média lisboeta, tendo a família assegurado uma formação secundária e universitária a Seomara, que se revelou uma aluna brilhante. Esse patamar de excelência seria uma marca na sua vida profissional. Ela foi professora de Ciências na Universidade de Lisboa e, antes, professora do ensino liceal; no seu percurso, revelou-se como investigadora, autora, principalmente de manuais didáticos, desenhadora e ilustradora. Seomara da Costa Primo destacou-se também no associativismo docente, participando com intensidade na imprensa.

Se a podemos considerar hoje uma mulher do seu tempo, ela apresenta-se-nos sobretudo como uma mulher além do seu tempo, uma intelectual (SIRINELLI, 1996), que ocupou um lugar pioneiro na defesa do papel ativo das mulheres na sociedade, defendeu a sua educação e se afirmou num universo predominantemente masculino. Ao longo da sua vida frequentou instituições de referência e travou debates em arenas significativas de discussão.

Foi uma personalidade ímpar que não se limitou à escala nacional, tendo realizado viagens ao estrangeiro em missões científicas. A sua figura tem sido relativamente esquecida, mas é um nome que deve ser destacado, pois exemplifica uma forma de estar no espaço público e de afirmar a profissão docente (LÔBO; FARIA, 2008; PERROT, 2015).

Depois de ter realizado, com distinção, o exame de instrução primária, Seomara da Costa Primo cursou o Liceu Maria Pia, que foi o primeiro liceu feminino português, onde concluiu, em 4 de agosto de 1911, o Curso Geral ( $2^{\mathrm{a}}$ secção) com a classificação de 17 valores. Continuou os seus estudos com a 
frequência do curso complementar de Ciências, no Liceu Passos Manuel, onde terminou o ensino secundário, em 27 de julho de 1913, com a nota final de 17 valores.

A sua formação universitária foi realizada na Faculdade de Ciências da Universidade de Lisboa, no curso de Ciências Histórico-Naturais, tendo-se diplomado em 1919, com a classificação final de 18 valores. Durante estes anos académicos, o seu valor foi reconhecido e recebeu vários diplomas de mérito (PRIMO, 1943). Complementarmente, frequentou também as cadeiras de Histologia e Embriologia na Faculdade de Medicina, na mesma Universidade, em 1917-1918. Aliás, exerceu o cargo de preparadora do Instituto de Histologia e Embriologia durante um ano, orientada por Celestino da Costa.

Seomara deixou aquelas funções para frequentar o Curso do Magistério Liceal na Escola Normal Superior, onde se diplomou e realizou o seu Exame de Estado, em 1922, com a classificação final de 18 valores. Este curso habilitou-a para o exercício da profissão docente, tendo desempenhado as funções de professora no Liceu Almeida Garret e, depois, no que lhe sucedeu - o Liceu Maria Amália Vaz de Carvalho. As duas designações da instituição liceal foram atribuídas, sucessivamente, ao antigo Liceu Maria Pia. Na realidade, Seomara Costa Primo regressava, como professora, após uma década, à escola onde fora aluna liceal.

Durante mais de vinte anos, no período de 1921 a 1942, Seomara foi simultaneamente professora do ensino liceal e docente universitária. Aliás, foi na condição de professora do ensino liceal que ela desenvolveu intensa atividade no campo pedagógico e associativo: integrou os corpos dirigentes da Federação das Associações dos Professores dos Liceus Portugueses, a partir de 1927, e proferiu diversas comunicações nos Congressos daquela associação e em encontros realizados em outros países, onde se deslocava muitas vezes acompanhada por seu pai, Manuel da Costa Primo.

Em 1942, defendeu o doutoramento em Ciências Biológicas (Botânica) e foi a primeira mulher a doutorar-se nesta área em Portugal. A partir de então, passou a dedicar-se às aulas, na universidade, e à investigação. A sua vida profissional passou a situar-se no mundo universitário, mas manteve sempre uma relação umbilical com o ensino secundário. Assim se compreende que o seu nome seja principalmente conhecido como autora de manuais e materiais didáticos de ciências naturais para o ensino secundário. Os manuais de Seomara têm traços distintivos, assim como os seus materiais didáticos (nomeadamente os quadros parietais), que apresentam uma notável qualidade estética na sua apresentação. As aguarelas, os carvões e outras ilustrações, muitas de sua autoria, expressam o rigor científico e o sentido de beleza com que estas obras eram concebidas.

Seomara da Costa Primo aposentou-se no ano de 1962, dando por finda uma carreira irrepreensível, brilhantemente dedicada ao ensino, à ciência e à 
participação cívica. Em 1986, faleceu na sua casa da Amadora, perto de Lisboa, na qual tinha vivido quase meio século; morreu no dia em que devia abandonar essa casa, para que ela fosse demolida.

FIGURA 1 - SEOMARA DA COSTA PRIMO NA SUA CASA, AMADORA, PORTUGAL

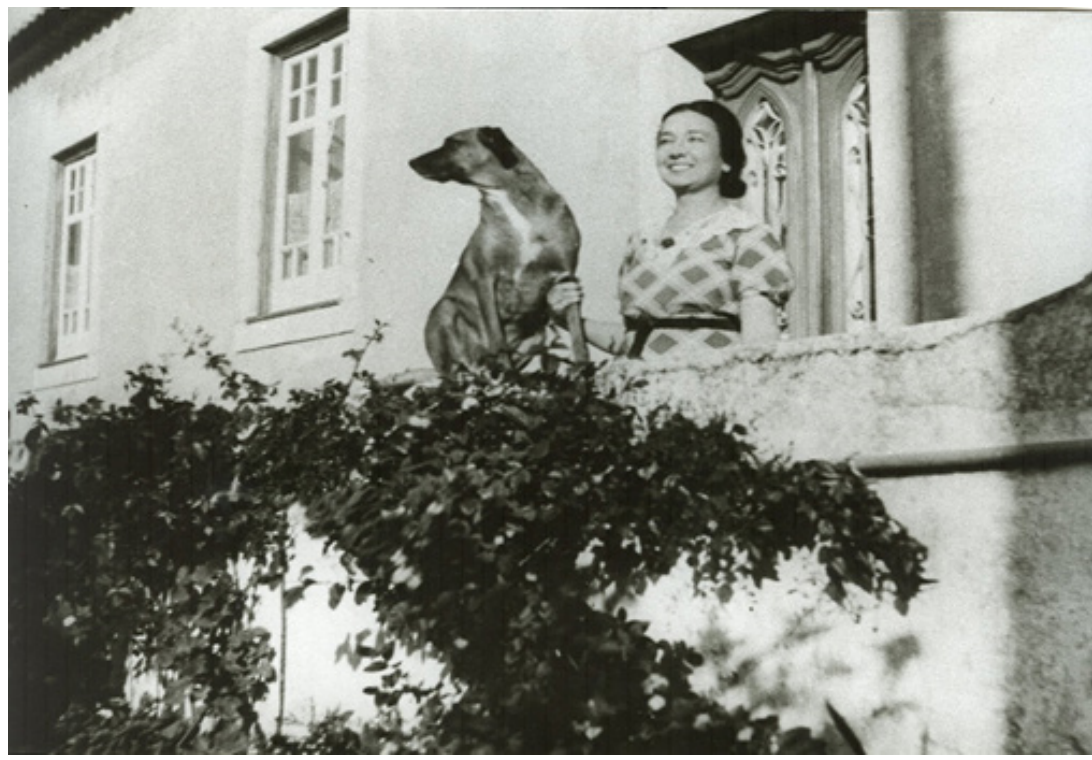

FONTE: Núcleo Museológico Seomara da Costa Primo (2017).

Um ano antes tinha afirmado, de forma paradigmática, o seu percurso vital: "Alunos e livros foram meus companheiros na vida; mais do que isso, eles foram a minha própria vida" (PRIMO apud CARVALHO, 2012, não p.). A escola da Amadora adotou o seu nome como patrona e inscreveu esta frase na sua entrada.

\section{Autora de manuais e professora no ensino liceal}

Como professora do primeiro Liceu feminino português, desde 1922, lecionou as disciplinas de Ciências Naturais (Botânica, Biologia, Zoologia) e Ciências Físico-Químicas, tendo percorrido os patamares próprios da profissão docente: primeiro foi professora provisória, depois professora agregada e, final- 
mente, em 1926, professora efetiva (PRIMO, 1943; CAVADAS; GUIMARÃES, 2010). A dimensão em que atinge maior notoriedade no exercício dessas funções é a de autora de manuais e compêndios para o ensino secundário. São livros didáticos de Botânica, Biologia e Zoologia, que se apresentam com numerosas ilustrações, harmonizando de forma cientificamente rigorosa texto e imagem.

Estes materiais didáticos expressam as novas correntes editoriais, mas há um cunho pessoal que os eleva a obras artísticas, nas aguarelas e nos carvões que a própria Seomara executa com rara beleza e que os transforma em objetos únicos. Autora de vários tipos de materiais didáticos, como os quadros parietais, neles imprime a mesma qualidade científica e artística; ainda hoje essas produções se encontram nas coleções histórias do património educativo que povoam as escolas mais antigas do ensino secundário português.

Contudo, importa não esquecer o campo de produção (BOURDIEU, 1991, 2004) em que Seomara da Costa Primo se movimentava e publicava as suas obras. Foi um campo fortemente controlado pelo poder político, em que o Estado Novo exercia a censura prévia sobre todas as formas de expressão. No campo educativo, a política do "livro único" foi instituída em 1935, tendo os manuais de cada disciplina de serem aprovados pelo Ministério da Educação Nacional. Era um processo complexo e dispendioso para os autores, que tinham de submeter as suas propostas de manuais ao exame e avaliação de uma comissão oficial. Esse processo reforçava fortemente o controlo político e ideológico do estado sobre os autores de manuais, os professores, as escolas e o sistema educativo, no seu todo, refletindo-se no autocontrole e autolimitação de quem escrevia e autocensurava as suas produções, sabendo que elas iam ser sujeitas ao crivo de uma censura ideológica e punitiva, à luz dos valores mais conservadores e autoritários do regime político. Era o império do medo, com a consequente desvalorização do espírito crítico nos processos de aprendizagem e na educação.

Nesse contexto, Seomara da Costa Primo revela toda a sua determinação e criatividade, desenvolvendo modalidades próprias para contornar (subtilmente) as prescrições emanadas do poder político quanto a esta matéria e impondo o seu nome como a autora privilegiada do seu campo disciplinar. Nos anos de chumbo do regime, os seus manuais de Botânica, de Biologia e de Zoologia, ilustrados e coloridos, tiveram sucessivas reedições, com uma presença constante nos liceus portugueses entre os anos 30 e 70 do século XX. Numa bibliografia sistematizada pelo Ministério da Educação, em 2006, no âmbito de uma exposição virtual dedicada a Seomara, são referenciados 37 títulos, tanto de edições como de reedições. 
FIGURAS 2, 3 E 4 - MANUAL ESCOLAR; QUADRO GERAL DOS GRUPOS VEGETAIS (ESTAMPA); ESTUDO PARA QUADRO PARIETAL SOBRE AS LEIS DE MENDEL, DE SEOMARA DA COSTA PRIMO
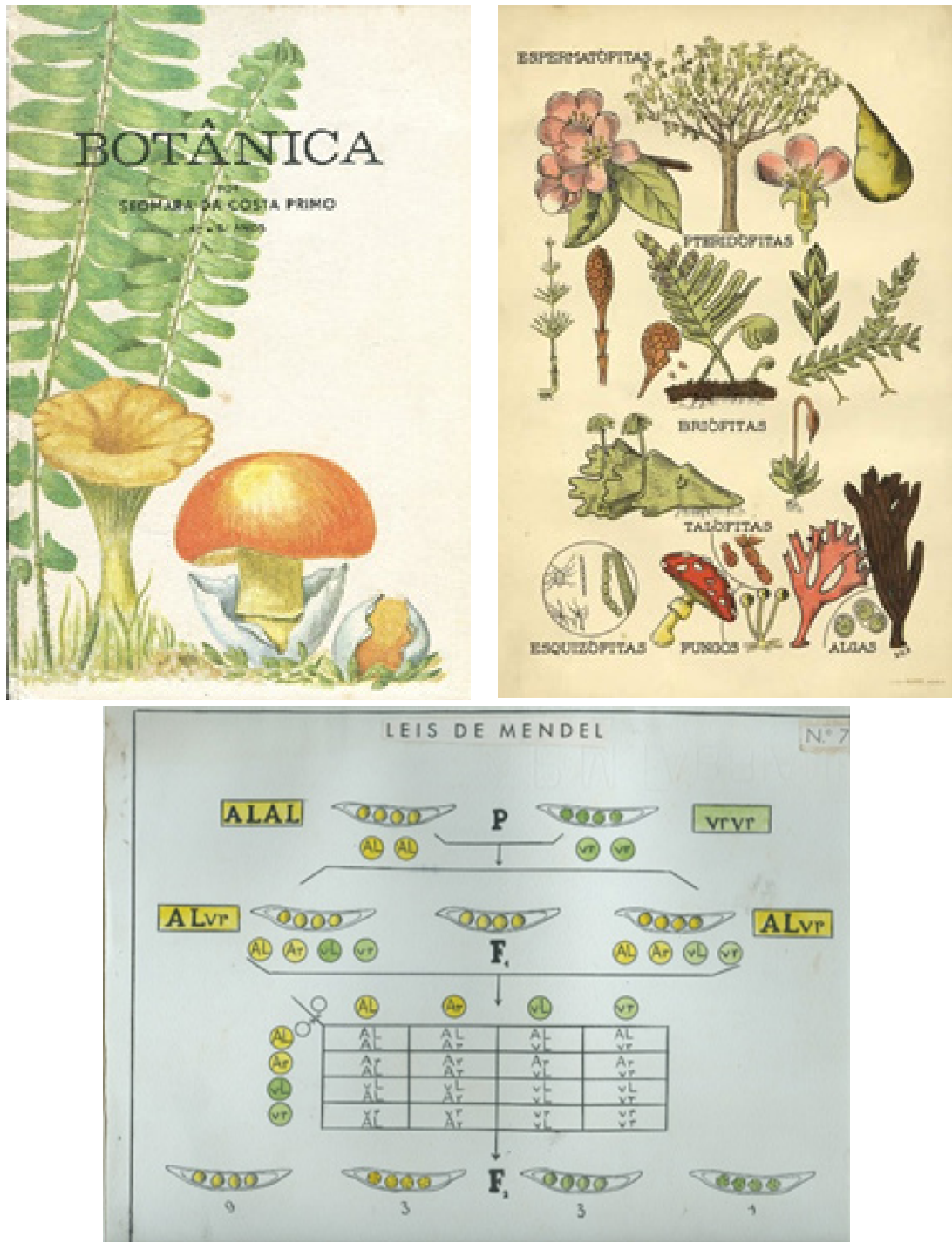

FONTE: Núcleo Museológico Seomara da Costa Primo (2017) e Exposição virtual sobre Seomara Costa Primo: vida e obra (PORTUGAL, 2006). 
As ilustrações dos manuais de Seomara da Costa Primo expressam o desenvolvimento da manualística, atribuindo uma importância crescente à imagem, que vai conquistando terreno, na mancha gráfica, ao texto (CAVADAS; GUIMARÃES, 2010). No entanto, as obras de Seomara expressam esse lugar das ilustrações na economia explicativa dos conteúdos, mas elas continuam a atribuir ao texto o lugar central desse processo.

Se uma imagem vale por mil palavras, é pelas emoções que suscita, pelos estímulos que cria e pelas simplificações a que conduz. Neste sentido, o texto é tão ou mais importante que a imagem pela simples razão de que é mais complexo, profundo e rigoroso... Deste ponto de vista, as imagens não servem a realidade, servem os seus autores. Sendo assim, Seomara da Costa Primo através dos manuais escolares usou a realidade como objecto, a fim de melhor exprimir o que queria explicar e mostrar. No caso das figuras analisadas, a imagem cumpriu com um significado rigoroso e pertinente a interpretação conceptual de Seomara, com o objectivo de favorecer o reconhecimento e a identificação pelos alunos do conteúdo em questão e de atingir níveis elevados de qualidade estética e beleza formal... aliás, a iconografia apresentada revelou sempre dependência textual e nunca o oposto. Essa opção mostra o papel central que ainda cabia ao texto nos manuais de ciências da altura, embora esse foco fosse diminuindo paulatinamente. (CAVADAS; GUIMARÃES, 2010, p. 9-10).

Esses mesmos autores realçam que "nos manuais de Seomara as imagens apresentam uma riqueza morfológica substancial, sendo inclusivamente inovadoras no uso corrente da fotografia e da cor, acompanhando o próprio avanço das técnicas gráficas" (CAVADAS; GUIMARÃES, 2010, p. 10) e a sua análise confirma, em bases científicas e consolidadas, a valorização da iconografia nas ilustrações de Seomara. O conjunto da obra didática e manualística revela a experiência significativa da autora e reflete a "consciência pedagógica de uma educadora incontornável” (CAVADAS; GUIMARÃES, 2010, p. 10) no campo educativo português. A beleza artística das suas aguarelas, carvões, estampas, desenhos e fotografias, que integram o seu espólio, ilumina essas dimensões profissionais e científicas da sua vida.

Seomara da Costa Primo foi uma defensora das metodologias ativas e as suas práticas pedagógicas focavam-se na observação direta, na experimentação, na (re)formulação de perguntas e respostas. Como professora, acreditava que cada aluno tinha um caminho próprio e ela apoiava esse percurso, escolhendo exercícios específicos em função das particularidades que cada um tinha. Esta conceção personalizada do ensino explica algumas das suas opções. 
Seomara foi uma apologista do cinema educativo, que introduziu no seu Liceu em 1929, com a apresentação do filme Chang e a publicação de um extenso artigo no suplemento do jornal O Século (o "Cinéfilo"), intitulado "Chang - Uma lição no Liceu Maria Amália Vaz de Carvalho". Nesse artigo faz uma breve história do cinema e realça as vantagens do cinema educativo como forma de aproximar os alunos da realidade. Seomara defendia também a correspondência interescolar, considerando-a um meio de união e solidariedade entre as crianças do mundo. Foi uma dimensão transnacional das suas conceções pedagógicas, que exprimiu também no interesse que manteve relativamente à Cruz Vermelha da mocidade, apresentando uma comunicação sobre o tema, em 1930, e, ainda nesse ano, uma conferência intitulada "A educação e a Cruz Vermelha infantil", patrocinadas pelo jornal O Século e o seu suplemento "Modas e Bordados", dirigido por Maria Lamas, em que dava a conhecer os objetivos e as realizações em prol da paz que a referida instituição internacional prosseguia.

Em 1929, Seomara tinha assistido a uma exposição didática realizada em Genebra e observara os trabalhos de crianças de 41 países; entusiasmada com a iniciativa, propunha-se impulsionar a adesão de Portugal a esta instituição e divulgar a sua ação entre os alunos dos liceus portugueses. As suas perspetivas sobre a educação e as suas preocupações pedagógicas revelaram-se na defesa da necessidade de adotar novos métodos de ensino, o que a conduziu à afirmação pública da sua crítica relativamente aos programas do ensino liceal. Coerente com a sua ação pedagógica, Seomara defendeu

A transformação dos métodos de ensino em métodos activos, que tendem a favorecer a actividade pessoal da criança, procurando rodeá-la das mesmas condições que encontrará na vida, levando-a a resolver problemas em que é colocada, dentro das suas forças e da sua mentalidade, o que é certo é que também nos nossos programas muito pouco se cuida dos problemas da vida. (PRIMO, 1930).

Seomara da Costa Primo desempenhou vários cargos e funções, com grande empenho pedagógico e cívico: foi membro de júris de exames de admissão ao estágio liceal, participou nas provas de admissão à Universidade do Porto, em exames de estado e na apreciação de exposições de trabalhos escolares. Foi também nomeada para integrar várias comissões, como a Comissão de Revisão dos Planos de Estudos e dos Programas do Ensino Liceal em 1942.

As questões relativas à condição da mulher foi outra das suas preocupações e exprimiu as suas ideias com clareza, defendendo a educação da mulher: 
Quanto mais esclarecida ... for [a mulher], tanto mais elevará a sua missão de mãe. A cultura nunca fará mal às raparigas ... é a mulher, de facto quem exerce mais influência no espírito dos filhos. Fomentar, pois, a sua cultura, elevar a sua mentalidade, é pedra-de-toque de um país verdadeiramente civilizado. (PRIMO, 1943).

Como membro dos corpos gerentes da Federação das Associações dos Professores dos Liceus Portugueses, desde 1927, apresentou diversas comunicações nos Congressos realizados pela associação: os Congressos do Ensino Secundário Oficial, realizados entre 1927 (o I Congresso) e 1931 e o I Congresso Nacional de Ciências Naturais, realizado em Lisboa, em 1941. Também participou ativamente em Congressos internacionais, tais como: o XI Congrès Internacional de l'Énseignement Secondaire, realizado em Haia, em 1929, como delegada da Federação das Associações dos Professores dos Liceus portugueses; e o III Congrès Bisannuel de la Fédération Universelle dês Associations Pédagogiques, realizado em Genebra, também em 1929, entre outros eventos similares.

A memória da professora liceal manteve-se, forte, carinhosa e impressiva nas suas alunas. É vivamente recordada nas palavras de Antera Valeriana de Seabra:

Fui aluna da Professora Seomara em Ciências físico-químicas e Ciências naturais no $4^{\circ}, 5^{\circ}$ e $6^{\circ}$ anos do liceu, portanto, de 1935 a 1938. Gostava muito das aulas dela e ela tinha aqueles livros maravilhosamente bem ilustrados - ela gostava muito de desenhar e pintar. As aulas eram muito práticas: ela levava para as aulas os caules cortados, as cebolas que observávamos ao microscópio e íamos ao laboratório observar o esqueleto humano, os músculos...ainda hoje sei muita coisa de Biologia graças àquela professora.... Era uma professora extraordinariamente pedagoga - tinha umas qualidades pedagógicas extraordinárias e era uma simpatia. Ela foi à nossa viagem de fim do curso do liceu -fomos lá acima ao Lindoso e foi sempre muito atenciosa e amiga, muito simples... comigo e com as outras minhas colegas.

Eu assisti ao seu doutoramento e... como era mulher foi bastante amachucada... ela não merecia aquele tratamento... O júri era composto por homens, com excepção da Doutora Branca, mas ela não era de Biologia era de Química...

Foi uma Professora a quem realmente muito fiquei a dever, que me empurrou para as Ciências, que me trazia problemas e exercícios e dizia "estes dois são para a Antera" e depois dava outros problemas diferentes às minhas colegas. 
A Seomara era fundamentalmente uma pedagoga e uma amante da profissão; ela vivia para os seus alunos, nunca se casou nem nada...tinha uma amizade muito especial pelos seus alunos e era uma Professora "com

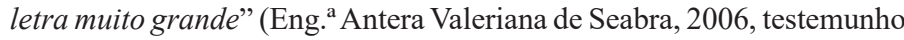
oral). (PORTUGAL, 2006).

As palavras de Laura Ayres revelam o mesmo carinho e reconhecimento pela figura paradigmática da professora que as marcou para a vida:

Conheci Seomara da Costa Primo nos últimos anos do curso liceal, no fim dos anos 30. Os quase cinquenta anos que me separam dessa data não fizeram apagar a memória da professora de excepção que as alunas da minha geração tiveram o privilégio de conhecer... Sobretudo, fiquei a dever-lhe o exemplo inesquecivel de alguém com o gosto pelo saber teórico e prático e com a atitude perante o ensino que a caracterizaram como uma profissional impar e que, sem dúvida, marcou profundamente as suas alunas, tanto no liceu como na Faculdade de Ciências. Relembrar Seomara da Costa Primo, a quem me ligaram laços de profundo respeito e amizade, é prestar-lhe a ainda que muito simples homenagem a que fez jus pelas suas elevadas qualidades profissionais e humanas. (Dr. ${ }^{a}$ Laura Ayres, 1986, testemunho). (PORTUGAL, 2006).

\section{A professora na universidade}

A carreira universitária de Seomara da Costa Primo iniciou-se em 1921, quando assumiu as funções de $2^{\circ}$ Assistente não remunerada do subgrupo de Botânica, tendo no ano seguinte continuado a exercer o cargo, mas de forma remunerada. Até 1934-1935 assegurou principalmente os trabalhos práticos dos cursos de Botânica Sistemática e Morfologia e Fisiologia Vegetais. Em 1934, foi proposto que ela exercesse, por contrato, o cargo de assistente encarregada do curso de Botânica, tendo então sido contratada para essas funções.

Foi um impulso importante na sua carreira académica e universitária, onde se afirmou e integrou a lista dos grandes nomes da botânica nacional (CAVADAS; GUIMARÃES, 2010). Seomara preocupou-se permanentemente com o ato educativo e não somente com a transmissão de conhecimentos, como sublinham Antunes e Galvão (2001). 
A tese de doutoramento de Seomara da Costa Primo, intitulada Contribuição para o estudo comparativo da acção do arsénio e da colciquina na célula vegetal, foi defendida em 1942, tendo sido aprovada com mérito absoluto. Ela foi a primeira mulher a doutorar-se em Ciências Biológicas. As provas do doutoramento foram noticiadas na imprensa e tiveram um impacto significativo na época, com a descrição detalhada das perguntas (relembre-se que as suas alunas refeririam a exigência de algumas questões que lhe colocaram, por comparação com a facilidade de outras feitas a candidatos do género masculino) e a calma e o rigor de Seomara nas respostas. Foi ainda salientada a forma efusiva como colegas e alunos felicitaram Seomara. No entanto, na memória de algumas alunas, ficou gravada a maneira pouco elegante como alguns membros (masculinos) do júri a questionaram durante as provas, considerando que havia uma intencionalidade expressa de a "amachucar".

\section{FIGURAS 5 E 6 - O DOUTORAMENTO DE SEOMARA DA COSTA PRIMO NA IMPRENSA DA ÉPOCA}

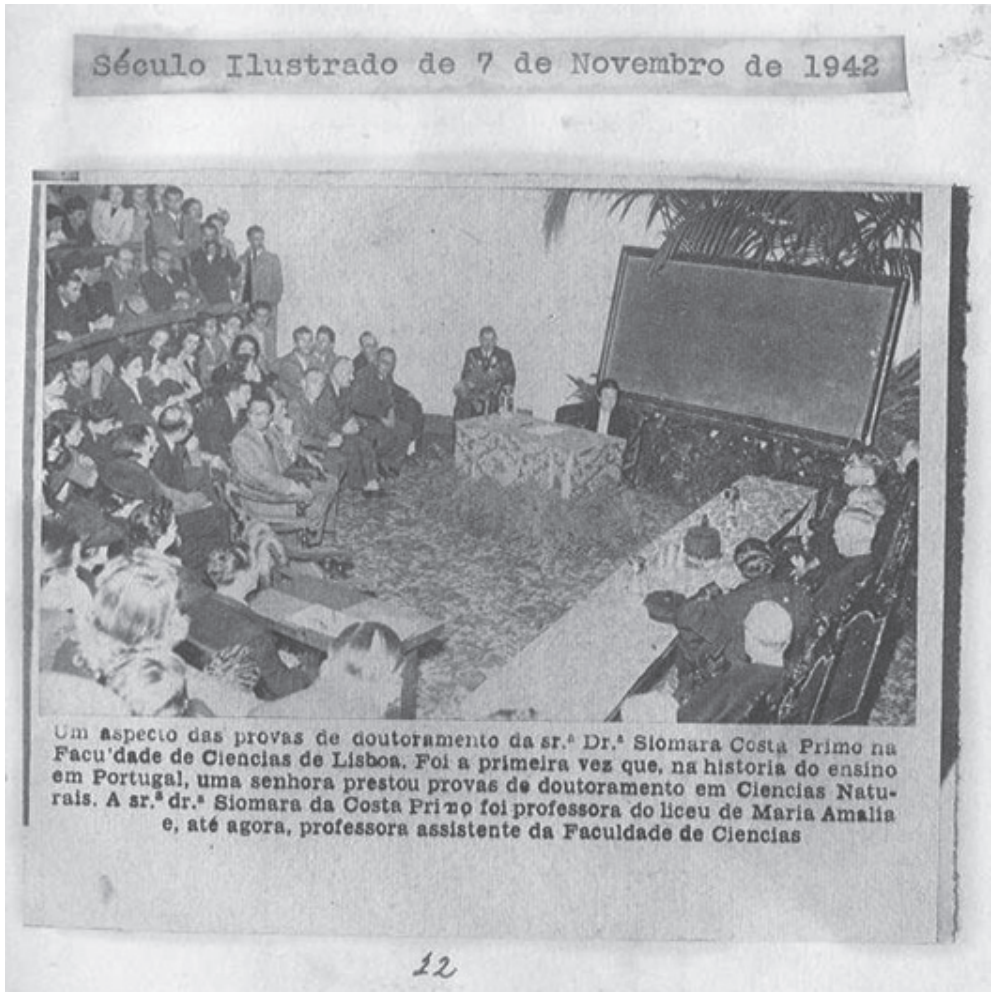




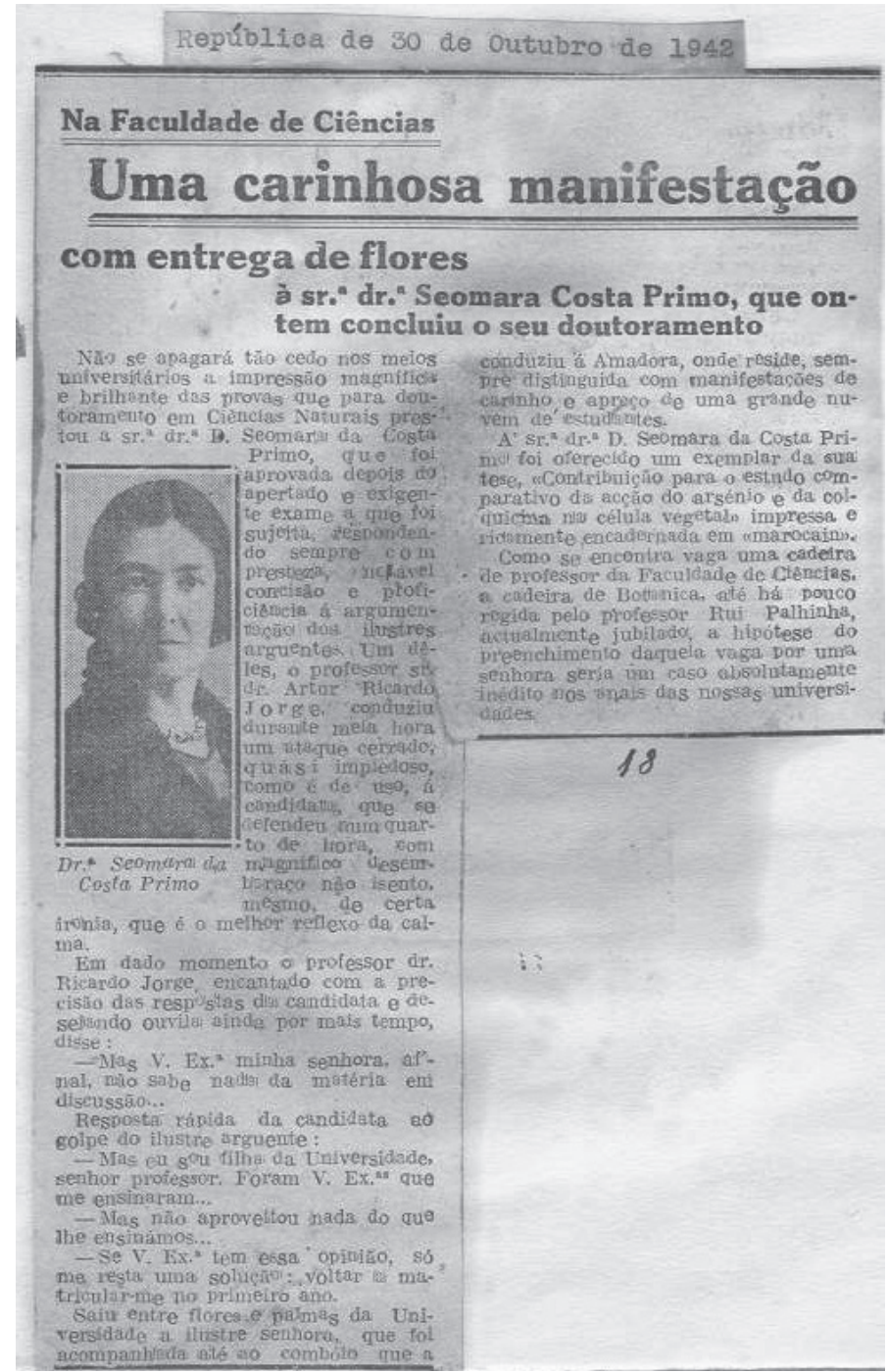

FONTE: Exposição virtual sobre Seomara Costa Primo: vida e obra (PORTUGAL, 2006).

Na sequência do Doutoramento, Seomara da Costa Primo foi nomeada $1^{\circ}$ Assistente do $2^{\circ}$ grupo (Botânica) da $3^{\mathrm{a}}$ secção da Faculdade de Ciências. No ano seguinte, em 1943, prestou provas públicas no concurso para o lugar de professor catedrático do mesmo $2^{\circ}$ grupo (Botânica), mas não se conhece a sua nomeação 
para esta categoria. Foi regente das disciplinas de Morfologia e Fisiologia Vegetais, Botânica Geral e Botânica Sistemática, entre outras, sendo mais tarde responsável pela cadeira de Desenho Biológico (1949). A lecionação desta última cadeira expressa de forma exemplar a associação que estabelecia entre a arte e a ciência.

Esta dimensão da arte na ciência, que iluminava um espírito de grande rigor, está presente no testemunho da sua aluna Salomé Soares Pais, que frequentou a Faculdade de Ciências na rua da Escola Politécnica:

[Seomara da Costa Primo] deslocava-se habitualmente junto de cada aluno que, em pé, no seu estirador, passava as aulas de Desenho Biológico, no $1^{\circ}$ andar da Faculdade de Ciências de Lisboa, na Rua da Escola Politécnica, tentando por vezes com dificuldade, fazer ressaltar um pormenor da folha ou da flor de uma Angiospérmica ou dar expressão ao bico do mais simples dos pássaros. Quando necessário, a Prof. Seomara pegava no lápis e, como boa desenhadora Biológica que era, rapidamente corrigia a perspectiva ou exprimia o rigor da nervação ou recorte da folha desenhada. (Salomé Soares Pais, Testemunho). (PORTUGAL, 2006).

Seomara atingiu, na sua atividade científica, uma escala internacional. Ela foi autora de artigos científicos, publicados em revistas da especialidade, tendo sido citada na imprensa estrangeira; foi também sócia de diversas sociedades científicas, como a Sociedade Portuguesa de Ciências Naturais, a Sociedade Portuguesa de Biologia, a Sociedade Broteriana e a Société Linnéenne de Lyon. Como autora, destacam-se as suas colaborações com os Arquivos da Universidade de Lisboa, o Bulletin de la Société Portugaise des Sciences Naturelles, o Boletim da Sociedade Broteriana, os Archives portugaises des sciences biologiques e as revistas Labor, Scientia e Naturalia (ANTUNES; GALVÃO, 2001). As suas viagens de estudo, de âmbito científico e pedagógico, levaram-na a França, a Alemanha, a Bélgica, a Holanda e a Suíça, onde participou em congressos e frequentou várias instituições científicas, como o Instituto Botânico de Berlim-Dahlem, Nymphenburg, Universidade de Iena.

\section{O lugar de Seomara da Costa Primo na memória e na história da educação}

As alunas de Seomara e as suas colegas professoras, assim como um número reduzido de investigadoras, assumiram como imperativo preservar a sua 
herança, os seus documentos e as memórias da mestre. No entanto, as publicações são em número reduzido, distinguindo-se os textos de Guida Carvalho (2010, 2003), Guida Carvalho e Capelão (2002) e de Helena Antunes e Cecília Galvão (2001). Na verdade, esta personalidade paradigmática da educação portuguesa reclama uma investigação mais aprofundada. Algumas questões se colocam, por exemplo: porque razão publica o seu último texto científico em 1943, quando continuou na docência e na Universidade até 1962? Porque não foi nomeada catedrática, apesar de ter sido aprovada no respetivo concurso, em 1943?

No entanto, no mundo virtual encontram-se bastantes informações, consequência do trabalho desenvolvido pelo Núcleo Museológico Seomara da Costa Primo, da Escola Secundária Seomara da Costa Primo, que constituiu, preserva e divulga o precioso espólio da sua patrona. Aliás, foi com base neste espólio que o Ministério da Educação de Portugal organizou a exposição virtual Seomara Costa Primo: vida e obra, datada de 2006. A referida Escola da Amadora reuniu, a partir de 1980, uma parte considerável do seu espólio bibliográfico e artístico, constituído por aguarelas, manuais escolares, publicações, apontamentos de Seomara, fotografias, objetos pessoais, recortes de imprensa e livros, num total de 600 espécimes. Esse espólio, reunido no Núcleo Museológico, foi constituído através de doações de entidades oficiais e particulares, nomeadamente da Escola Secundária Maria Amália Vaz de Carvalho, do Museu-Escola Jardim Botânico e da Dr. ${ }^{a}$ Maria Luísa Azevedo Neves. O Núcleo Museológico Seomara da Costa Primo é da responsabilidade das professoras Maria José Capelão e Guida Carvalho.

A Escola Secundária Maria Amália Vaz de Carvalho também possui exemplares que pertencem ao espólio de Seomara, relacionado com o ensino liceal: manuais escolares, quadros parietais (ou murais), livros de homenagem com elevado número de assinaturas que evidenciam as relações humanas que manteve com os seus alunos e com os colegas. Por seu lado, o espólio de Seomara da Costa Primo associado à investigação e ao ensino universitário está depositado, em grande parte, na biblioteca do Instituto Botânico da Faculdade de Ciências da Universidade de Lisboa (ANTUNES; GALVÃO, 2001).

\section{Conclusão}

Seomara da Costa Primo é uma figura paradigmática, que fez parte da geração que lutou pela afirmação da mulher na sociedade do seu tempo e num universo predominantemente masculino, como era a universidade. A sua ação cívica e envolvimento associativo, as suas ideias e o seu perfil profissional 
permitem-nos colocá-la na vanguarda em defesa de um país moderno, livre e democrático, em diálogo com as outras sociedades e universos pedagógicos e científicos. No entanto, quase toda a sua vida profissional decorreu sob um regime autoritário e concentracionário, sujeitando a ação pessoal, social e profissional aos mecanismos da censura sobre a liberdade de expressão e de controlo político-ideológico sobre a vida quotidiana e profissional. Seomara construiu o seu espaço próprio de ação entre estes condicionalismos, no ensino liceal (em que sempre atuou, mesmo que só como autora de manuais) e na universidade (a que sempre esteve ligada), no mundo editorial e no associativismo, agindo de forma determinada, exprimindo as suas ideias convictamente e encontrando mecanismos subtis de contornar as dificuldades para as divulgar. Mulher de espírito interventivo e inovador, de enorme coerência entre o que defendia e o que praticava na sua atividade docente, os testemunhos que muitos alunos nos dão revelam uma personalidade "atenciosa, amiga, simples, paciente, pouco comunicativa, extremamente correta, sabedora, modesta e generosa" (CARVALHO, 2010, p. 208), algo distante e profissionalmente irrepreensível. Elina Guimarães, na hora da morte de Seomara, enalteceu as suas qualidades de mulher cientista, pedagoga e cidadã e reclamou a necessidade de manter viva a sua memória exemplar, pois com grande talento "subiu, com simplicidade, tão alto" e "serviu dedicadamente a ciência, o seu país e, desse modo, as suas compatriotas" (GUIMARÃES, 1986, p. 29).

\section{REFERÊNCIAS}

ANTUNES, H.; GALVÃO, C. Seomara da Costa Primo: a investigadora, docente, a mulher. In: SIMÕES, A. (Org.). Memórias de professores cientistas. Lisboa: Faculdade de Ciências da Universidade de Lisboa, 2001. p. 38-42.

BOURDIEU, P. Le champ littéraire. Actes de la recherche en sciences sociales, vol. 89, p. 3-46, septembre 1991 .

BOURDIEU, P. Os usos sociais da ciência: por uma sociologia clínica do campo científico. São Paulo: UNESP, 2004.

CARVALHO, G. A investigação sobre Seomara. Núcleo Museológico Seomara da Costa Primo, Amadora, Portugal, 13 abr. 2012. Disponível em: $<$ http://nuclemuseologicoseomara.blogspot.com.br/search/label/Sobre\%20Seomara>. Acesso em: 25 maio 2017.

CARVALHO, G. Seomara da Costa Primo. La découverte de sa méthode d'enseignement à partir des cahiers de ses étudiants. In: MEDA, J.; MONTINO, D.; SANI, R. (eds). 
School Exercise Books. A Complex Source for a History of the Approach in Schooling and Education in the 19th and 20th Centuries. Macerata: Edizioni Polistampa, 2010.

CARVAlHO, G. Seomara da Costa Primo. In: NÓVOA, A. (dir.). Dicionário de Educadores Portugueses. Porto: Asa, 2003. p. 1120-1123.

CARVAlHO, G.; CAPELÃO, M. J. Seomara da Costa Primo na imprensa. Santarém: Cadernos do Projeto Museológico sobre Educação e Infância, 2002.

CAVADAS, B.; GUIMARÃES, F. As ilustrações dos manuais de Botânica de Seomara da Costa Primo. In: DUARTE, J. B. (Ed.). Manuais escolares e dinâmica da aprendizagem. Lisboa: Edições Universitárias Lusófonas, 2010. p. 117-142.

GUIMARÃES, E. A primeira catedrática em Ciências Biológicas. Diário de Notícias Mulher, p. 29, 23 abr. 1986.

LÔBO, Y.; FARIA, L. (Orgs.). Vozes femininas do império e da República. Rio de Janeiro: Quartet: FAPERJ, 2008.

NÚCLEO MUSEOLÓGICO SEOMARA DA COSTA PRIMO. Escola Secundária Seomara da Costa Primo, Amadora, Portugal, 2017. Disponível em: <http://nuclemuseologicoseomara.blogspot.pt/>. Acesso em: 25 maio 2017.

PERROT, M. Minha História das Mulheres. São Paulo: Ed. Contexto, 2015.

PORTUGAL. Ministério da Educação. Seomara Costa Primo: vida e obra. Exposição virtual. Lisboa: Ministério da Educação, 2006. Não paginado. Disponível em: $<$ http://193.137.22.223/pt/patrimonio-educativo/museu-virtual/exposicoes/seomara-costa-primo-vida-e-obra/apresentacao/>. Acesso em: 25 maio 2017.

PRIMO, S. da C. Curriculum vitae: Seomara da Costa Primo. Lisboa: Faculdade de Ciências de Lisboa, 1943.

PRIMO, S. da C. A mulher contemporânea, entrevista. Diário de Lisboa, 21 maio 1943.

PRIMO, S. da C. A educação e a Cruz Vermelha da mocidade. Modas \& Bordados, $\mathrm{n}^{\circ}$ 957, 1930.

SEOMARA, uma mulher do seu tempo. Produção: Catarina Vidigal. Realização: Ricardo Ferreira. Portugal: Yamagoe Produções, 2007. [documentário]. Disponível em: $<$ https://www.youtube.com/watch?v=1TJZDABOWnk\&feature=youtu.be $>$. Acesso em: 25 maio 2017.

SIRINELLI, J. F. Os intelectuais. In: RÉMOND, R. (Org.). Por uma História política. Rio de Janeiro: UFRJ; Fundação Getúlio Vargas, 1996. p. 231-269.

Texto recebido em 12 de junho de 2017. Texto aprovado em 21 de junho de 2017. 